University of Nebraska - Lincoln

DigitalCommons@University of Nebraska - Lincoln

Publications, Agencies and Staff of the U.S.

Department of Commerce

U.S. Department of Commerce

2011

\title{
Seasonality of calving and predation risk in bottlenose dolphins on Little Bahama Bank
}

\author{
Holly Fearnbach \\ University of Aberdeen, holly.fearnbach@noaa.gov \\ John Durban \\ University of Aberdeen \\ Kim Parsons \\ University of Aberdeen \\ Diane Claridge \\ Bahamas Marine Mammal Research Organisation
}

Follow this and additional works at: https://digitalcommons.unl.edu/usdeptcommercepub

Part of the Environmental Sciences Commons

Fearnbach, Holly; Durban, John; Parsons, Kim; and Claridge, Diane, "Seasonality of calving and predation risk in bottlenose dolphins on Little Bahama Bank" (2011). Publications, Agencies and Staff of the U.S. Department of Commerce. 260.

https://digitalcommons.unl.edu/usdeptcommercepub/260

This Article is brought to you for free and open access by the U.S. Department of Commerce at DigitalCommons@University of Nebraska - Lincoln. It has been accepted for inclusion in Publications, Agencies and Staff of the U.S. Department of Commerce by an authorized administrator of DigitalCommons@University of Nebraska - Lincoln. 
MARINE MAMMAL SCIENCE, **(*): ***_***(***2011)

(C) 2011 by the Society for Marine Mammalogy

DOI: $10.1111 /$ j.1748-7692.2011.00481.x

\title{
Seasonality of calving and predation risk in bottlenose dolphins on Little Bahama Bank
}

\author{
Holly FearnBaCH \\ School of Biology, \\ Lighthouse Field Station, \\ George Street, \\ University of Aberdeen, \\ Cromarty, Ross-shire IV11 8YJ, Scotland \\ E-mail: holly.fearnbach@noaa.gov \\ JOHN DURBAN \\ School of Biology, \\ Lighthouse Field Station, \\ George Street, \\ University of Aberdeen, \\ Cromarty, Ross-shire IV11 8YJ, Scotland \\ and \\ Bahamas Marine Mammal Research Organisation, \\ PO Box AB20714, \\ Marsh Harbor, Abaco, Bahamas \\ and \\ Center for Whale Research, \\ 355 Smugglers Cove Road, \\ Friday Harbor, Washington 98250, U.S.A.

\section{KIM PARSONS} \\ School of Biology, \\ Lighthouse Field Station, \\ George Street, \\ University of Aberdeen, \\ Cromarty, Ross-shire IV11 8YJ, Scotland \\ and \\ Bahamas Marine Mammal Research Organisation, \\ PO Box AB20714, \\ Marsh Harbor, Abaco, Bahamas \\ Diane Claridge \\ Bahamas Marine Mammal Research Organisation, \\ PO Box AB20714, \\ Marsh Harbor, Abaco, Bahamas
}

Most studies of seasonal reproduction in odontocetes have considered bottom-up forcing through seasonal changes in the physical environment and/or prey availability (Wells et al. 1987, Read 1990, Urian et al. 1996, Mann et al. 2000, McGuire and Aliaga-Rossel 2007, Westgate and Read 2007), which are typically more pronounced 


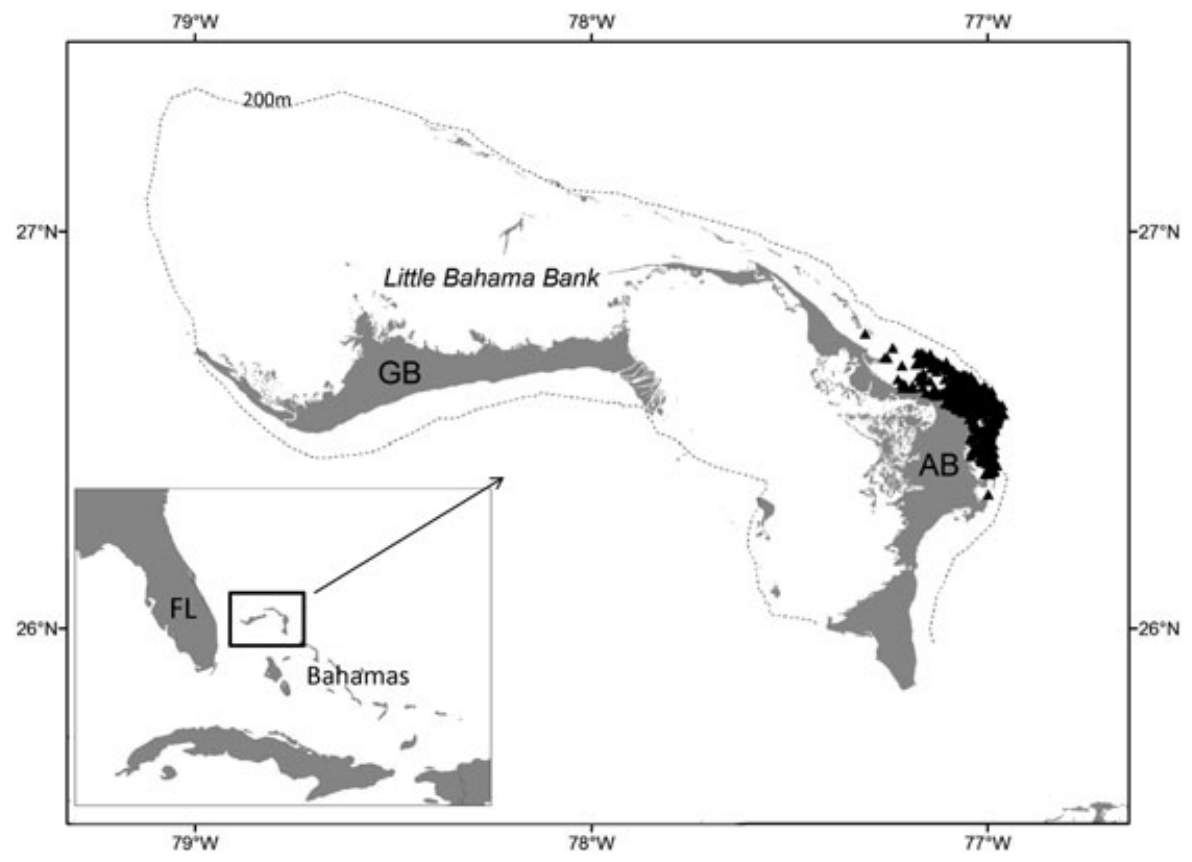

Figure 1. Map of Little Bahama Bank, around Abaco Bahama (AB) and Grand Bahama (GB) Islands. The bank is surrounded by the deep waters of the NW Atlantic Ocean, with the $200 \mathrm{~m}$ depth contour represented by a broken line. Locations of 788 dolphin encounters between 1992 and 2007 are represented by solid triangles off the east side of Abaco Island where surveys were conducted. The insert shows the position of the study area in the northern Bahamas off the east coast of Florida (FL).

in high latitudes. In contrast, there has been little consideration of top-down selection through seasonal changes in predation pressure. Predation pressure by sharks has been shown to affect delphinid habitat use and group size (Norris and Dohl 1980, Wells et al. 1987, Heithaus 2001, Heithaus and Dill 2002), but the influence of predation pressure on reproductive patterns of dolphin populations has rarely been assessed. Here, we report on a distinct seasonal peak in calving for bottlenose dolphins (Tursiops truncatus) using Little Bahama Bank, despite its tropical latitude and describe an inverse seasonal peak in the risk of predation by sharks, inferred by the incidence of fresh shark-bite wounds (Heithaus 2001). We suggest seasonal changes in the environment that might mediate increased predation risk and hypothesize that this may be a selective force for calving seasonality.

Little Bahama Bank $\left(\sim 26^{\circ} \mathrm{N}, \sim 77^{\circ} \mathrm{W}\right)$ comprises part of the northern Bahamas and encompasses the two main islands of Great Abaco and Grand Bahama (Fig. 1). This carbonate bank is approximately $17,000 \mathrm{~km}^{2}$ in size (approximately $65 \%$ covered by water), characterized by shallow waters (average $<7 \mathrm{~m}$ deep) and chains of small islands, and is bounded on all sides by the deep $(>500 \mathrm{~m})$ waters of the subtropical NW Atlantic Ocean. Approximately 1,000 bottlenose dolphins inhabit the bank (Durban 2002), and individuals from this inshore dolphin population have not been sighted in the surrounding pelagic waters, despite extensive survey effort over 
Table 1. Total number of dolphins and neonates identified and the number of individuals with fresh shark-bite wounds for each month pooled over all years (1992-2007). Also presented are the total number of dolphin groups encountered in each month, and the number of years in which each month was surveyed. Water temperature data are also presented by month for March 2007 to February 2008, recorded at a coastal mangrove creek within the study area, ${ }^{1}$ along with the average surface water temperature during dolphin encounters (1992-2007), where available. Tropical cyclone seasonality is indicated $\left.{ }^{* * *}\right)$, based on long-term records reported in Landsea (1993), along with named storms whose centers passed within $60 \mathrm{~nm}$ of the study site during the 1992-2007 study period (http://www.hurricanecity.com/city/abacoisland.htm).

\begin{tabular}{|c|c|c|c|c|c|c|c|}
\hline Month & $\begin{array}{c}\text { Years } \\
\text { surveyed }\end{array}$ & $\begin{array}{c}\text { Groups } \\
\text { encountered }\end{array}$ & $\begin{array}{l}\text { Total } \\
\text { IDs }\end{array}$ & Neonates & $\begin{array}{c}\text { Fresh } \\
\text { wounds }\end{array}$ & $\begin{array}{l}\text { Water tem- } \\
\text { perature }{ }^{\circ} \mathrm{C} \\
\text { (at dolphins) }\end{array}$ & $\begin{array}{l}\text { Cyclone season } \\
\text { (Abaco storms) }\end{array}$ \\
\hline January & 10 & 43 & 67 & 3 & 0 & 22.5 (NA) & - \\
\hline February & 8 & 58 & 76 & 4 & 1 & $24.4(23.6)$ & - \\
\hline March & 9 & 63 & 95 & 1 & 0 & $23.1(22.3)$ & - \\
\hline April & 8 & 39 & 77 & 0 & 0 & $25.1(22.8)$ & - \\
\hline May & 5 & 27 & 31 & 0 & 0 & 26.5 (NA) & - \\
\hline June & 9 & 85 & 85 & 0 & 0 & $28.6(27.4)$ & $* * *$ \\
\hline July & 7 & 56 & 76 & 0 & 2 & $31.1(29.2)$ & *** (Bertha 1996) \\
\hline August & 6 & 65 & 76 & 0 & 4 & $31.0(28.2)$ & $\begin{array}{r}* * *\left(\text { Erin } 1995^{\mathrm{a}}\right) \\
\quad(\text { Dennis } 1999)\end{array}$ \\
\hline September & 2 & 123 & 83 & 0 & 4 & $29.8(28.4)$ & $\begin{array}{c}\text { *** (Floyd 1999), } \\
\quad(\text { Frances 2004 }) \\
(\text { Jeanne 2004 })\end{array}$ \\
\hline October & 9 & 138 & 107 & 0 & 3 & $28.0(27.2)$ & $* * *$ \\
\hline November & 8 & 54 & 79 & 3 & 0 & $24.3(26.2)$ & - \\
\hline December & 5 & 48 & 55 & 5 & 2 & 24.3 (NA) & - \\
\hline
\end{tabular}

${ }^{1}$ Unpublished data from Craig Layman, Florida International University, 3000 NE 151st Street, North Miami, FL 33181.

${ }^{a}$ No field effort was conducted in the 2 mo directly following each of these hurricanes.

more than $16 \mathrm{yr}$, and therefore, this population appears to be restricted to this shallow bank system (Parsons et al. 2006). Seasonal variability in surface water temperature on Little Bahama Bank is limited, but temperatures are moderately elevated in summer compared to winter (Table 1). This increase in summer temperatures is coincident with tropical cyclones in the NW Atlantic (Vecchi and Soden 2007), which typically occur between June and October (Landsea 1993). To examine seasonal differences, we defined a 6 mo "summer" period (May-October), characterized by increased water temperatures and encompassing the entire season of tropical cyclones, and a 6 mo "winter" period (November-April), characterized by cooler water temperatures and a complete absence of cyclonic activity (Table 1).

Part of this population has been monitored annually since 1992 through boatbased photo-identification surveys in a $160 \mathrm{~km}^{2}$ study site on the east side of Abaco Island ( $\sim 26^{\circ} 33^{\prime} \mathrm{N}, \sim 77^{\circ} 04^{\prime} \mathrm{W}$; Fig. 1 ). A total of 251 distinctly marked individual dolphins were identified from 788 different dolphin groups encountered in this study area between 1992 and 2007, based on high-quality photographs (photographic processing methods described in Durban et al. 2000). Although surveys were not conducted year round in every year of the study, the population was surveyed in 
every month, when pooled across years. The median number of individual dolphins encountered each month, pooled over all years, was 77 (minimum 31, maximum 107) (Table 1). The level of coverage was consistent across seasons, with 185 different individuals documented in "summer" (from 1,665 dolphin identifications) and 175 in "winter" (1,236 identifications).

All encounter photographs were examined to detect newborn dolphins. Neonates were easily distinguished based on small body size (typically less than one-third the size of the mother), dark coloration, and floppy dorsal fin and were often observed surfacing in echelon position next to an attendant adult. However, to standardize for age in this analysis, we designated a calf to be a neonate only when there was clear evidence of changes in pigment around linear "folds" oriented dorsoventrally on the body, resulting from folding of the fetus in utero. Sixteen neonates were identified during the $16 \mathrm{yr}$ study, and seven of these neonates were repeatedly identified throughout the year following first sighting. Photographic analysis revealed that fetal folds were typically only evident for approximately $1 \mathrm{mo}$ in this warm-water environment, compared to a period of several months and even years in bottlenose dolphins from more temperate habitats (Grellier 2000) and therefore provided a reliable indicator of recent birth.

All encounter photographs were also examined to document fresh shark-bite wounds on individuals. Fresh wounds do not, of course, inform us of mortality events as a result of predation, but we assume that they provide an indicator of predation pressure. Wounds were classified as shark bites based on a semicircular shape matching a shark's jaw and marks resembling teeth marks were observed in association with most large wounds. Additionally, fresh wounds were identified based on a dark tone (black and white images) or red color (digital images) from exposed blood or muscle (Corkeron et al. 1987a, b; Orams and Deakin 1997; Heithaus 2001). Sixteen fresh shark-bite wounds were identified in total, comprising adult males (2), adult females (3), adults of unknown gender (3), subadults (2), and juveniles (6). Although constrained by small sample size, this relatively high proportion of juveniles with fresh wounds might imply the targeting of young animals by predatory sharks, and we note also that all three adult females with fresh wounds had dependent calves at the time. Analysis of within-year resightings, possible for nine of these dolphins, documented that these wounds only appear fresh (red or dark) for typically around a month, and therefore, we consider fresh wounds to be a sensitive indicator of the timing of shark attacks. Similar healing rates were reported in another warm-water study area off Australia (Corkeron et al. 1987a, Orams and Deakin 1997), where the complete closure of a fresh shark-bite wound was observed to occur within $30 \mathrm{~d}$ and all that remained after $45 \mathrm{~d}$ was "an obvious indented white un-pigmented scar" (Orams and Deakin 1997). Wounds from skin and blubber biopsies from dolphins in our Abaco study site were also reported to be "closed" (covered by epidermal tissue) after $30 \mathrm{~d}$ (Parsons et al. 2003).

To assess monthly variability in both calving and shark bite wounding rates, data across 16 yr (1992-2007) were pooled into 12 calendar months to count both the number of neonates and individuals with fresh shark-bite wounds in each monthly interval. To control for survey effort, and the degree to which the population was sampled, the number of neonates/newly wounded individuals was represented as a proportion of the total number of individuals identified in each month, pooled across all years. Because the sample sizes of both neonates and newly wounded dolphins were low, and the total number of identifications varied across the months, point estimates of proportions will vary in how well they represent the true proportion of calves/newly 
wounded dolphins in the population. To account for inherent uncertainty in these estimates of proportions, we adopted a Bayesian model for the estimation of the proportions, to represent uncertainty in the form of probability distributions (Gelman et al. 1995). The number of neonates/individuals with fresh wounds in each month was modeled as binomially distributed from the total number of individuals identified in that month. This allowed the binomial proportions to represent an estimate of the proportion of individuals that were neonates/newly wounded. Each monthly binomial proportion was initially assigned a flat prior distribution between 0 and 1 , which was updated, conditional on the data to estimate the posterior distribution for each monthly proportion. We used the WinBUGS software (Lunn et al. 2000) to implement Markov Chain Monte Carlo (MCMC) sampling to simulate sequences of values from the posterior distributions conditional on the observed data. The sampled values were then used to construct box plots of the posterior distributions for parameters of interest and estimate summary statistics for the posterior distributions.

To examine seasonal differences, we modified our Bayesian model to have a separate probability distribution underlying the proportions of calves/individuals with new wounds in both winter and summer. In particular, instead of a separate prior distribution for each month, we adopted a separate flat prior probability distribution for each season. When the estimates for the two seasonal distributions were made in the same MCMC run, we calculated the proportion of the MCMC sampled values, where the winter proportion of calves/wounds exceeded that from the summer (or vice versa), providing an estimate of the probability that the proportions were higher in one season than the other, while accounting for the variability in each seasonal distribution.

Despite uncertainty due to sample sizes (see error bars), there were clear differences across months in the proportion of individuals that were new calves (Fig. 2), with neonates only identified during the "winter" months. The calving rate peaked in December, with a posterior median for the proportion of individuals that were neonates of $0.10(95 \%$ Probability Interval $[\mathrm{PI}]=0.04-0.19)$ and was lowest in October (posterior median $=0.01,95 \%$ PI $=0.00-0.03$ ) (Fig. 2). Notably, almost all calves $(15 / 16$ or $94 \%)$ were born during 4 mo (November-February) of the winter period. As a result, there was marked difference in the monthly average calf proportion between seasons. The calf proportion in winter (posterior median $=0.09$, 95\% PI $=0.06-0.14)$ was significantly greater than that in the summer period (posterior median $=0.003,95 \% \mathrm{PI}=0.00-0.02$ ), with no overlap of the posterior distributions and therefore a high probability $(P=1)$ that the summer and winter calf proportions were different.

Most $(13 / 16,81 \%)$ of the shark-bite wounds we observed were acquired during a 4 mo period (July-October) within the summer season for tropical cyclones and increased water temperatures. The wounded proportion was highest in both August and September, with a posterior median for the proportion of individuals that possessed fresh wounds of 0.06 (95\% PI $=0.02-0.13$ and $0.02-0.12$, respectively) and was lowest in March (posterior median $=0.01,95 \% \mathrm{PI}=0.00-0.04$; Fig. 3). The wounded proportion was significantly higher in summer (posterior median $=0.07$, $95 \% \mathrm{PI}=0.04-0.12$ ) compared to winter (posterior median $=0.02,95 \% \mathrm{PI}=$ $0.01-0.05$ ). There was some overlap in the ranges of posterior distributions for these two estimates, but little overlap in the regions of highest probability density, and therefore, a very high probability $(P=0.99)$ that the summer and winter average wound proportions were different. Notably, the majority (11/16) of the documented wounds were observed immediately following either the direct passage of hurricane 


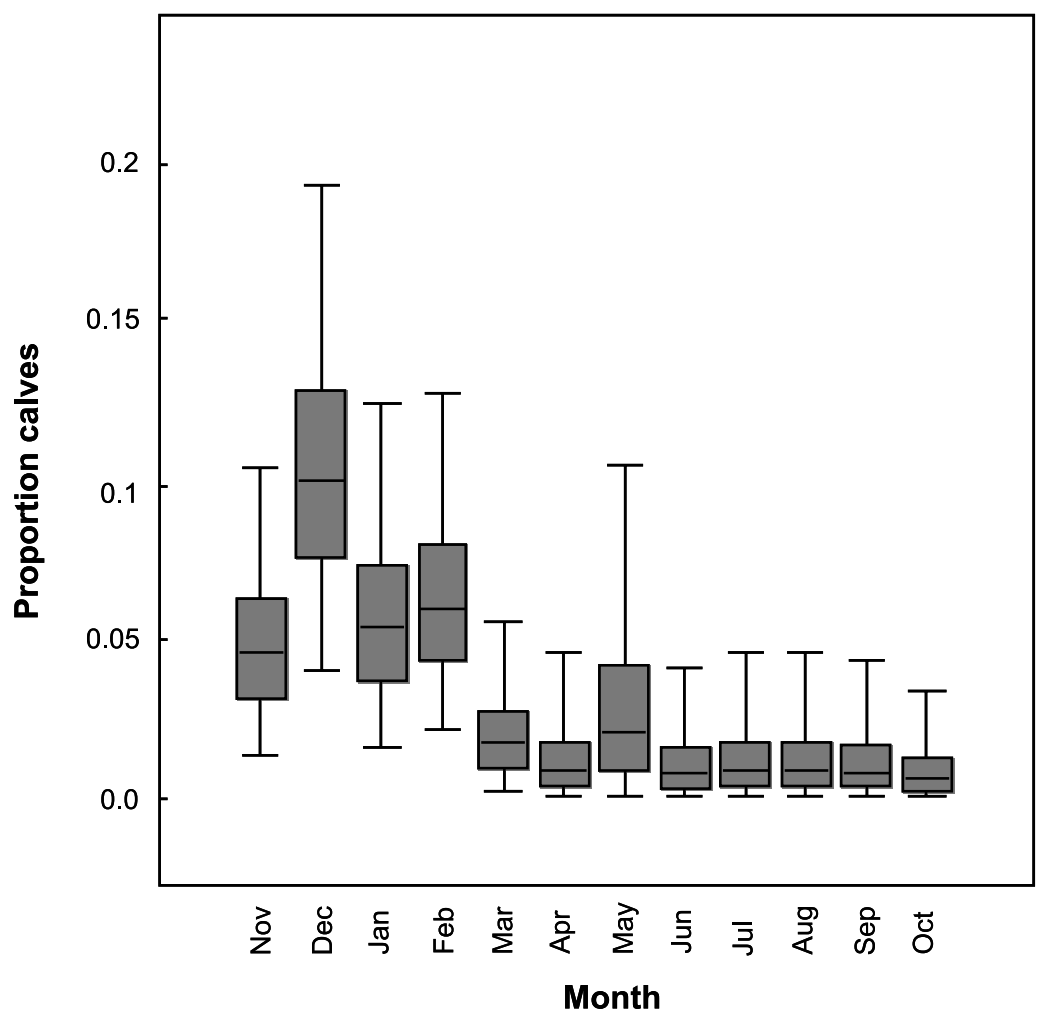

Figure 2. Box plot of the number of neonates as a proportion of the total number of individuals identified in each month. Vertical lines represent the intervals encompassing 95\% of the distribution, the boxes represent the central $75 \%$ interquartile range, and horizontal lines represent the posterior medians.

Bertha over Little Bahama Bank in July 1996 or the joint impact of direct hits from Hurricanes Dennis and Floyd in late August and September 1999.

These data describe distinct calving seasonality for dolphins on Little Bahama Bank, with all neonates documented during the winter months and none documented during the 7 mo with the highest water temperatures. This is similar to findings from higher latitude study sites, where distinct calving seasonality of odontocetes has been suggested to be linked to seasonal changes in water temperature and/or changes in prey (Read 1990, Urian et al. 1996, Haase and Schneider 2001, Thayer et al. 2003, Westgate and Read 2007). However, there are notable contrasts with these studies, as calving in our study is inversely related to summer increases in water temperature, and the temperature variability on Little Bahama Bank is relatively minor compared to higher latitudes.

We cannot rule out the possibility of calving in response to a seasonal shift in prey availability, as we do not have detailed data on feeding habits. It is also possible that even small increases in water temperature in this shallow water system create an environment that is too physiologically demanding in summer. High costs of maintaining a stable body temperature, when confronted with suboptimal ambient 


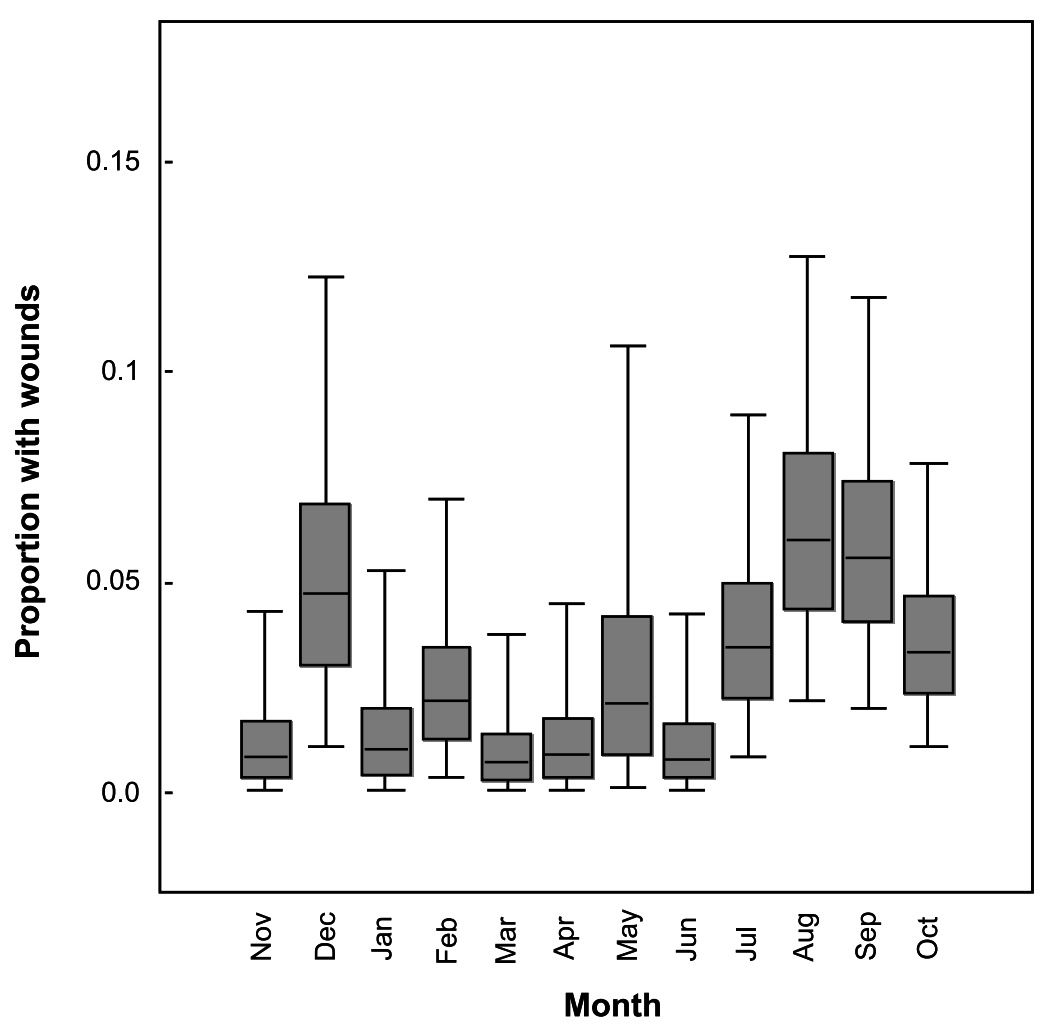

Figure 3. Box plot of the number of individuals with fresh shark-bite wounds as a proportion of the total number of individuals identified in each month. Vertical lines represent the intervals encompassing $95 \%$ of the distribution, the boxes represent the central $75 \%$ interquartile range, and horizontal lines represent the posterior medians.

temperatures (high or low), have been shown to lead to changes in reproduction and survival of several mammalian populations (Ohsawa and Dunbar 1984, Rutberg 1987, Dunbar 1990, Boyd 1996, Hill et al. 2000). However, the inverse correlation between calving seasonality and the acquisition of fresh shark-bite wounds suggest that seasonal changes in the environment may have also selected indirectly for calving seasonality by driving shifts in distribution and habitat use of dolphins and/or predatory sharks that have increased predation risk.

Unfortunately, data on shark movements is lacking from our study area, and equal-area coverage surveys for dolphins have not been conducted year round to provide a robust assessment of changes in dolphin distribution. Nonetheless, 13 of 16 fresh shark-bite wounds on dolphins were documented in the summer months, indicating a seasonal change in dolphin and shark interactions. We suggest that dolphins seeking cooler oceanic waters, or alternate prey sources, may spend more time in summer close to the deeper, exposed waters at the edge of the bank, which in turn may expose them to increased predation risk from oceanic sharks, particularly tiger sharks, that are known to prey on dolphins (Corkeron et al. 1987a, $b$; Cockcroft et al. 1989; Cockcroft 1991; Heithaus 2001). There may also be seasonal inshore 
movements of sharks, but although predatory sharks are common in the deep waters surrounding Little Bahama Bank, they are rarely sighted in the shallow, protected waters on the bank. ${ }^{1}$

The selective disadvantage of calving in summer may be accentuated by acute weather events, specifically the incidence of hurricanes. Hurricanes are a key feature of climatic and seasonal variability in the environment of the NW Atlantic (Landsea 1993, Webster et al. 2005, Vecchi and Soden 2007). These storms have been shown to have significant impact on both marine and terrestrial ecosystems (Spiller $e t$ al. 1998, Walther et al. 2002, Harley et al. 2006) and have been implicated in the mass stranding of cetaceans (Mignucci-Giannoni et al. 2000). The wind-driven wave heights and storm surge during intense hurricanes easily exceed the shallow water depth on Little Bahama Bank, making the shallow waters uninhabitable to dolphins. Although we have one anecdotal report of dolphins in a protected creek during Hurricane Bertha in 1996, we suspect that the primary survival response is to seek this deeper water habitat at the edge of the bank, which in turn exposes them to increased predation risk from oceanic sharks. Most (11/16) of the fresh sharkbite wounds were documented immediately following either the direct passage of Hurricane Bertha over Little Bahama Bank in July 1996 or the joint impact of direct hits from Hurricanes Dennis and Floyd in late August and September 1999. Unfortunately, photo-identification effort was limited in the months immediately following hurricanes in recent years. Nonetheless, these data suggest that predation risk is increased by these acute weather events. Notably, all neonates documented during this study were outside of the hurricane season for the NW Atlantic (JuneOctober, Landsea 1993), and only two calves were documented in the three calendar months prior to the onset of hurricane season. We suggest that this may be a response to the selective disadvantage of rearing a young calf during this potentially dangerous time (Miller et al. 2010).

\section{ACKNOWLEDGMENTS}

This study was made possible with financial support from Earthwatch Institute, Friends of the Environment (Abaco, Bahamas), The Carnegie Trust from the University of Scotland and The Mammal Society, with permission to conduct research granted by the Bahamas Department of Marine Resources. Many Earthwatch volunteers, volunteer BMMRO staff members, and student interns assisted tirelessly in data collection. We are grateful to Paul Thompson, Beth Scott, and Andy Foote for comments on an earlier version of this manuscript.

\section{LITERATURE CiTED}

Boyd, I. J. 1996. Individual variation in the duration of pregnancy and birth date in the Antarctic fur seals: The role of the environment, age and sex of fetus. Journal of Mammalogy 77:124-133.

Cockcroft, V. G. 1991. Incidence of shark bites on Indian Ocean hump-backed dolphins (Sousa plumbea) off Natal, South Africa. Report of the International Whaling Commission (Special Issue 12):277-282.

\footnotetext{
${ }^{1}$ Unpublished data from Diane Claridge, Bahamas Marine Mammal Research Organisation, 2010.
} 
Cockcroft, V. G., G. Cliff and G. J. B. Ross. 1989. Shark predation on Indian Ocean bottlenose dolphins (Tursiops truncatus) off Natal, South Africa. South African Journal of Zoology 24:305-310.

Corkeron, P. J., R. J. Morris and M. M. Bryden. 1987a. A note on healing of large wounds in bottlenose dolphins (Tursiops truncatus). Aquatic Mammals 13:96-98.

Corkeron, P. J., R. J. Morris and M. M. Bryden. 1987b. Interactions between bottlenose dolphins and sharks in Moreton Bay, Queensland. Aquatic Mammals 13:109-113.

Dunbar, R. I. M. 1990. Environmental determinants of fecundity in klipspringer (Oreotragus oreotragus). African Journal of Ecology 28:307-313.

Durban, J. W. 2002. Bayesian methods for marine mammal population assessment. Ph.D. thesis, University of Aberdeen, Aberdeen, Scotland. 199 pp.

Durban, J. W., K. M. Parsons, D. E. Claridge and K. C. Balcomb. 2000. Quantifying dolphin occupancy patterns. Marine Mammal Science 16:825-828.

Gelman, A., J. B. Carlin, H. S. Stern and D. B. Rubin. 1995. Bayesian data analysis. Chapman and Hall, London, UK.

Grellier, K. 2000. Reproductive biology of female bottlenose dolphins (Tursiops truncatus) using the Moray Firth, Scotland. M.Sc. thesis, University of Aberdeen, Aberdeen, Scotland. $73 \mathrm{pp}$.

Haase, P. A., and K. Schneider. 2001. Birth demographics of bottlenose dolphins (Tursiops truncatus) in Doubtful Sound, Fiorland, New Zealand-preliminary findings. New Zealand Journal of Marine and Freshwater Research 35:675-680.

Harley, C. D. G., A. R. Hughes, K. M. Hultgren, et al. 2006. The impacts of climate change in coastal marine systems. Ecology Letters 9:228-241.

Heithaus, M. R. 2001. Shark attacks on bottlenose dolphins (Tursiops aduncus) in Shark Bay, Western Australia: Attack rate, bite scar frequencies and attack seasonality. Marine Mammal Science 17:526-539.

Heithaus, M. R., and L. M. Dill. 2002. Food availability and tiger shark predation risk influence bottlenose dolphin habitat use. Ecology 83:480-491.

Hill, R. A., J. E. Lycett and R. I. M. Dunbar. 2000. Ecological and social determinants of birthing intervals in baboons. Behavioral Ecology 11:560-564.

Landsea, C.W. 1993. A climatology of intense (or major) Atlantic hurricanes. Monthly Weather Review 121:1703-1713.

Lunn, D. J., A. Thomas, N. Best and D. Spieglehalter. 2000. WinBUGS-A Bayesian modeling framework: Concepts, structure and extensibility. Statistics and Computing 10:325-337.

Mann, J., R. Connor, L. M. Barre and M. R. Heithaus. 2000. Female reproductive success in bottlenose dolphins (Tursiops sp.): Life history, habitat provisioning, and group size effects. Behavioral Ecology 11:210-219.

McGuire, T. L., and E. R. Aliaga-Rossel. 2007. Seasonality of reproduction in Amazon river dolphins (Inia geoffrensis) in three major river basins of South America. Biotropica 39:129-135.

Mignucci-Giannoni, A. A., G. M. Toyos-Gonzalez, J. Perez-Padilla, M. A. Rodriguez-Lopez and J. Overing. 2000. Mass stranding of pygmy killer whales (Feresa attenuata) in the British Virgin Islands. Journal of the Marine Biological Association of the United Kingdom 80:759-760.

Miller, L. J., A. D. Mackey, T. Holland, M. Solangi and S. A. Kuczaj. 2010. Potential effects of a major hurricane on Atlantic bottlenose dolphin (Tursiops truncatus) reproduction in the Mississippi Sound. Marine Mammal Science 26:707-715.

Norris, K. S., and T. P. Dohl. 1980. The structure and functions of cetacean schools. Pages 211-261 in L. M. Herman, ed. Cetacean behavior: Mechanisms and functions. John Wiley and Sons, New York, NY.

Orams, M. B., and R. B. Deakin. 1997. Report on the healing of a large wound in a bottlenose dolphin (Tursiops truncatus). Pages 170-173 in M. Hindell and C. Kemper, eds. Marine mammal research in the Southern Hemisphere. Volume 1. Status, ecology and medicine. Surrey, Beatty \& Sons, Chipping, Norton. 
Ohsawa, H., and R. I. M. Dunbar. 1984. Variations in the demographic structure and dynamics of gelada baboon populations. Behavioral Ecology and Sociobiology 15: $231-240$

Parsons, K. M., J. W. Durban and D. E. Claridge. 2003. Comparing two alternative methods for sampling small cetaceans for molecular analysis. Marine Mammal Science 19: $224-231$

Parsons, K. M., J. W. Durban, D. E. Claridge, D. L. Herzing, K. C. Balcomb and L. R. Noble. 2006. Population genetic structure of coastal bottlenose dolphins (Tursiops truncatus) in the northern Bahamas. Marine Mammal Science 22:276-298.

Read, A. J. 1990. Reproductive seasonality in harbour porpoises (Phocoena phocoena) from the Bay of Fundy. Canadian Journal of Zoology 68:284-288.

Rutberg, A. T. 1987. Adaptive hypotheses of birth synchrony in ruminants: An interspecific test. The American Naturalist 30:692-710.

Spiller, D. A., J. B. Losos and T. W. Schonener. 1998. Impact of a catastrophic hurricane on island populations. Science 281:695-697.

Thayer, V. G., A. J. Read, A. S. Friedlander, et al. 2003. Reproductive seasonality of western Atlantic bottlenose dolphins off North Carolina, U.S.A. Marine Mammal Science 19:617-629.

Urian, K. W., D. A. Duffield, A. J. Read, R. S. Wells and E. D. Shell. 1996. Seasonality of reproduction in bottlenose dolphins (Tursiops truncatus). Journal of Mammalogy 77: $394-403$.

Vecchi, G. A., and B. J. Soden. 2007 Effect of remote sea surface temperature change on tropical cyclone potential intensity. Nature 450:1066-1070.

Walther, G-R, E. Post, P. Convey, et al. 2002. Ecological responses to recent climate change. Nature 416:389-395.

Webster, P.J., G. J. Holland, J. A. Curry and H. R. Chang. 2005. Changes in tropical cyclone number, duration, and intensity in a warming environment. Science 309:1844-1846.

Wells, R. S., M. D. Scott and A. B. Irvine. 1987. The social structure of free-ranging bottlenose dolphins. Pages 247-305 in H. H. Genoways, ed. Current mammalogy. Volume 1. Plenum Press, New York, NY.

Westgate, A. J., and A. J. Read. 2007. Reproduction in short-beaked common dolphins (Delphinus delphis) from the western North Atlantic. Marine Biology 150:1011-1024.

Received: 23 March 2010

Accepted: 20 February 2011 